\title{
Living Locally, Dreaming Globally Transnational Cultural Imaginings and Practices in the Hmong Diaspora
}

Roberta Julian

\section{Introduction}

This chapter is part of a larger project exploring the impact of globalisation on Australian national identity. In this chapter I examine identification processes among a small Asian community in Australia by drawing on my research with Hmong in Tasmania. My involvement with the Hmong community in Tasmania began in 1993 when some colleagues and I from the University of Tasmania were approached by Vue Thaow, the first Hmong person to settle in Tasmania, to undertake research on Hmong settlement experiences. We secured funding from the then Bureau of Immigration, Multicultural and Population Research to undertake a study of refugee settlement in Tasmania. This examined the settlement experiences of the largest refugee communities in the state at that time, namely, Hmong, Vietnamese, Chilean, El Salvadoran, Polish and Kurdish (Julian et al. 1997). 
Vue Thaow arrived in Tasmania, the small island state at the southeastern tip of Australia, in 1973 as a student under the Colombo Plan. After the fall of Vientiane in 1975, he sponsored his wife and two children to Australia, followed by his parents, his siblings, other members of his clan and then the relatives of those who had married into his clan. Thus began two decades of chain migration of Hmong refugees from Laos to Tasmania, via refugee camps (mainly Ban Vinai) in Thailand. At the turn of the century the emerging Hmong community in Tasmania numbered about 500 and was represented by seven clans. When I met Vue Thaow and the Hmong in Tasmania I began a fascinating journey of discovery of Hmong people who are now dispersed throughout the world; that is, the Hmong diaspora.

This chapter on the Hmong diaspora is based on almost ten years of association with Hmong people - mainly in Tasmania and the United States, but also more recently, in Thailand. I make use of data that has been collected through what could be labelled an ethnographic methodology. This has involved a wide variety of methods: observation, participant observation, in-depth semi-structured interviews, a survey and structured interviews, document analysis (including books, newsletters, articles on the internet, keynote addresses at conferences), analysis of scholarly publications (by Hmong and non-Hmong), autobiographies and biographies of Hmong (such as students and women), cultural artefacts and other media (for example, storycloths or paj ndau), plays (for example, 'Highest Mountain Fastest River'), museum displays (for example, 'Hmong of the Mountains'), comedy skits and videos (for example, Tou Ger Xiong's 'Hmong Means Free'), poetry and short stories by Hmong-Americans (for example, in the journal Paj Ntaub Voice and the newsletter Hnub Tshiab).

The research on which this chapter is based has been guided by two general questions: 'who are the Hmong?' and 'what does it mean to be Hmong?' These questions are of interest to sociologists and anthropologists (for example, Tapp 2000, Schein 1999 and Lee 1996) in that they provide an opportunity to examine processes of identity construction under conditions of postmodernity and in the context of globalisation. Most importantly, however, these 
questions are of immediate significance to members of the Hmong diaspora themselves. Illustrative of this concern with identity is the fact that the Hmong National Development (HND) conference selected 'The Complexity of Hmong Identity' as its 2002 theme and 'Connecting Across Communities' as its theme for 2004.

Over the past ten years, my interest in the Hmong community has led me to be involved in a wide range of activities relating to Hmong settlement, including presenting papers at the First Hmong National Development Conference in Minneapolis in 1995, the fourth conference held in Denver in 1998 and the seventh held in Milwaukee in 2002. The arguments in this chapter have been rehearsed at these and other sites (such as universities in Thailand) and have benefited from invaluable feedback from Hmong audiences. Nevertheless, the views expressed here remain those of an 'outsider' and are subject to the limitations (as well as the possible strengths) of such a position. I present them here as arguments that are open to debate and contestation and I look forward to a continuing dialogue with Hmong people in various parts of the world on issues relating to Hmong identity.

\section{Globalisation, Diaspora and Identity}

This chapter explores the construction of a diasporic Hmong identity in the context of the contradictions of globalism and localism. It argues that the success with which the Hmong are constructing a global identity suggests that the diaspora, as a form of social organisation, has the potential to transcend and succeed the nation-state, thus bridging the gap between the global and the local (compare Cohen 1997). It explores processes of identity construction at four levels: local, national, regional and global. It argues that there are two major foci of identity construction among the Hmong, namely, at the local and the global level, and that rather than being contradictory these processes reinforce one another.

In exploring Hmong identity, it is important to recognise, first, that 'one identity cannot be defined in isolation: the only way to circumscribe an identity is by contrasting it against other 
identities. Consequently, identity is an ambiguous notion. It gets its meaning from what it is not, from the Other' (Martin 1995: 6). Furthermore, it 'requires the presence of the Other, that is, the perception of someone different and the establishment of a relationship with him/her/them' (Martin 1995: 6). Thus, as Martin (1995: 16) argues 'identity, far from being a state characterising isolated groups, is a construction in progress which brings meaning and value (positive or negative) to a relationship or a set of relationships with Others' (my emphasis).

Stuart Hall argues that globalisation has 'the effect of contesting and dislocating the centred and "closed" identities of a national culture' (1992: 309). He defines globalisation as 'those processes, operating on a global scale, which cut across national boundaries, integrating and connecting communities and organisations in new space-time combinations, making the world in reality and in experience more interconnected' (1992: 299). A definition by Rex points even more directly to the possibility of emergent forms of social organisation resulting from globalisation. For Rex, globalisation refers to a process in which 'the bounding of social life by such political units as nation-states has been superseded by a state of affairs, in which the social relations and networks in which individuals are involved, as well as the cultural influences to which they are subject, tend to have global, rather than purely national character' (Rex 1995: 21-2). For Cohen diasporas are 'particularly adaptive forms of social organisation' (1997: 176) in the age of globalisation.

Globalisation and transnational ties open up new sets of relationships for Hmong people which destabilise the taken-forgrantedness of past relationships. They thus challenge previous identities. Globalisation means identity change. As with all communities, however, it is important to recognise that diasporas are not unified and homogeneous. As Avtar Brah (1996: 184) has noted, they are 'lived and re-lived through multiple modalities' as 'differentiated, heterogeneous and contested spaces, even as they are implicated in the construction of a common "we"'.

So who is engaged in this (re)construction of Hmong identity in the 'age of globalisation'? Who are the participants? In 
what ways does their participation direct the process of identity construction and the content(s) of emergent Hmong identities? The construction of national and cultural identities is often examined only from the point of view of those in power. However, as Denis-Constant Martin has pointed out:

It takes political brokers and ordinary people ... to tangle strategies and feelings into a narrative which will raise an echo (1995: 11).

This chapter examines the dynamic interplay between who is participating and the emergent meanings of Hmong identity that result from their participation. More specifically, it focuses on the role of Hmong women in the (re)construction of Hmong identities in the diaspora.

\section{Hmong Identification Processes}

Following Goffman (1959), I wish to focus my discussion on the 'work' being done by Hmong with respect to identity; that is, the presentation of self or more broadly 'identity work'. This concept highlights the fact that identity construction is not just about the development of appropriate narratives, but also (and some would argue, fundamentally) involves social action in the context of established and emergent social relationships. In other words, there is a very important, but often overlooked, performative dimension to identification.

To feed back into the issues raised earlier I will analyse this 'identity work' at four different levels (inter-related empirically): local, national, regional and global. In examining identity construction it is worth acknowledging that '[identity] narratives means being meant for others as well as oneself, several versions of the same narrative may be uttered, or ... the same narrative may comprise several levels, because it aims at different targets' (Martin 1995: 8). The analysis here is based on the example of the Tasmanian Hmong. Furthermore:

... (a) $n$ individual can change his identifications in the course of his life; that is, he may, at a time, feel more 
concerned by, more attracted to one particular identity narrative and, at another time, by another. The same individual can, at the same time, relate to several narratives and, to a certain extent, cope with the contradictions between them. As a matter of fact, multiple identification is the rule. Identifications are usually nested like Russian dolls, although the intensity with which individuals identify to groups and narratives is variable' (Martin 1995: 14).

The following discussion of identification processes among the Hmong adopts a framework of multiple identification. Not only does it recognise the existence of multiple sites of identification (for example, ethnic, familial, gendered, occupational) but it recognises the existence of several layers, or levels, of ethnic identification. I will begin my discussion of Hmong identity at the local level, followed by the national, regional and global levels. See Table 1 opposite.

\section{'Identity Work': The Local Level}

In Tasmania, the work that goes into identity construction at the local level is predominantly understood in terms of 'maintaining cultural identity' as encouraged in government policy statements on Australian multiculturalism (for example, OMA 1989). In the political context, this is largely carried out by male leaders in the Hmong community. In this endeavour, they are supported by migrant support workers. This work predominantly involves presenting the Hmong community, as Hmong, to Tasmanians and generating a positive and acceptable image to the Tasmanian people. Given Tasmania's reliance on tourism, it is perhaps not surprising that this 'identity work' tends to construct Hmong identity as 'the exotic Other', as a marketable tourist commodity.

This encourages an essentialist notion of Hmong identity which homogenises what is, despite its small size, an heterogeneous 'community'. This homogenising process is evident in the words of a young Hmong man who, when asked what it means to be Hmong, gave the following response: 
Table 1: Hmong Identification Processes

\begin{tabular}{|c|c|c|}
\hline Level & Identity & Processes of Identity Construction \\
\hline Global & Hmong & $\begin{array}{l}\text { - Diasporic identity } \\
\text { - Directed by Hmong in the US } \\
\text { - Essentialist and based on a 'reinvented' } \\
\text { tradition } \\
\text { - International marriages } \\
\text { - Women as agents of social change } \\
\text { - young people and popular culture } \\
\text { - eg. identity construction via the internet }\end{array}$ \\
\hline Regional & Asian & $\begin{array}{l}\text { - Asian identity within Australia } \\
\text { - Victims of discrimination vs. the 'Asian' face } \\
\text { of Tasmania } \\
\text { - Links with Laotians but not with } \\
\text { Vietnamese } \\
\text { - Regional identity undeveloped } \\
\text { - Limited ties with Laos }\end{array}$ \\
\hline National & $\begin{array}{l}\text { Australian? } \\
\text { Hmong-Australian? }\end{array}$ & $\begin{array}{l}\text { - majority }(78 \%) \text { are Australian citizens } \\
\text { - Australian identity non-existant } \\
\text { - Hmong-Australian identity problematic } \\
\text { - limited participation in Australian society } \\
\text { - social closure } \\
\text { - few Hmong-Australian relationships } \\
\text { - second generation assimilating }\end{array}$ \\
\hline Local & Hmong & $\begin{array}{l}\text { - Maintaining 'cultural identity' } \\
\text { - The 'exotic other' } \\
\text { - Cultural identity as a marketable commodity } \\
\text { - Essentialist } \\
\text { - Grounded in a patriarchal clan structure } \\
\text { - Endogamous } \\
\text { - Women as cultural icons } \\
\text { - Hmong identity - commodified, trivialised } \\
\text { and marginalised } \\
\text { - Resistance from young women }\end{array}$ \\
\hline
\end{tabular}


There is definitely less freedom in Hmong culture. It's not like a class system but it is like a caste system. Individuals have their own place and roles to play. The father of the family has the final decision-making. The mother's role is to look after the children and the children's role is to achieve things they are expected to achieve, like school and to respect their elders ... Freedom to us is like freedom but in quotes.

The Hmong identity is remembered and reconstructed in Australia as an essentialist identity. Furthermore, it is grounded in a patriarchal clan structure. Thus to 'maintain cultural identity' implies the maintenance of the Hmong clan structure. The strategies have been very successful thus far. In Australia, there have been almost no out-marriages to date.

It is important to note, however, that the clan takes on a new meaning in the context of constructing a Hmong identity in Australia. As a Hmong man explains:

We live in Australia and I think that clan struggle will not exist any more because we will not have a powerful clan or group who can do politics or that sort of thing. Basically we are looking at clan support. We are looking at the word 'Hmong' as brother to cover everyone. We are looking for people in the Hmong society to raise the status of the whole community.

While some have argued that the significance of the clan is weakening in Australia, I would argue that we are witnessing a transformation in the meaning of the clan in light of attempts to construct an homogeneous Hmong community that 'fits' the exigencies of Australian multiculturalism in practice (compare Hage 1998).

Hmong femininity is constructed to support this clan structure and the image of the 'exotic Other'. Women become the bearers of cultural tradition - cultural icons whose images are a marketable commodity. The symbolic site of this process is Salamanca Market in Hobart, a major tourist attraction. One of the successful economic projects among some Hmong in Hobart 


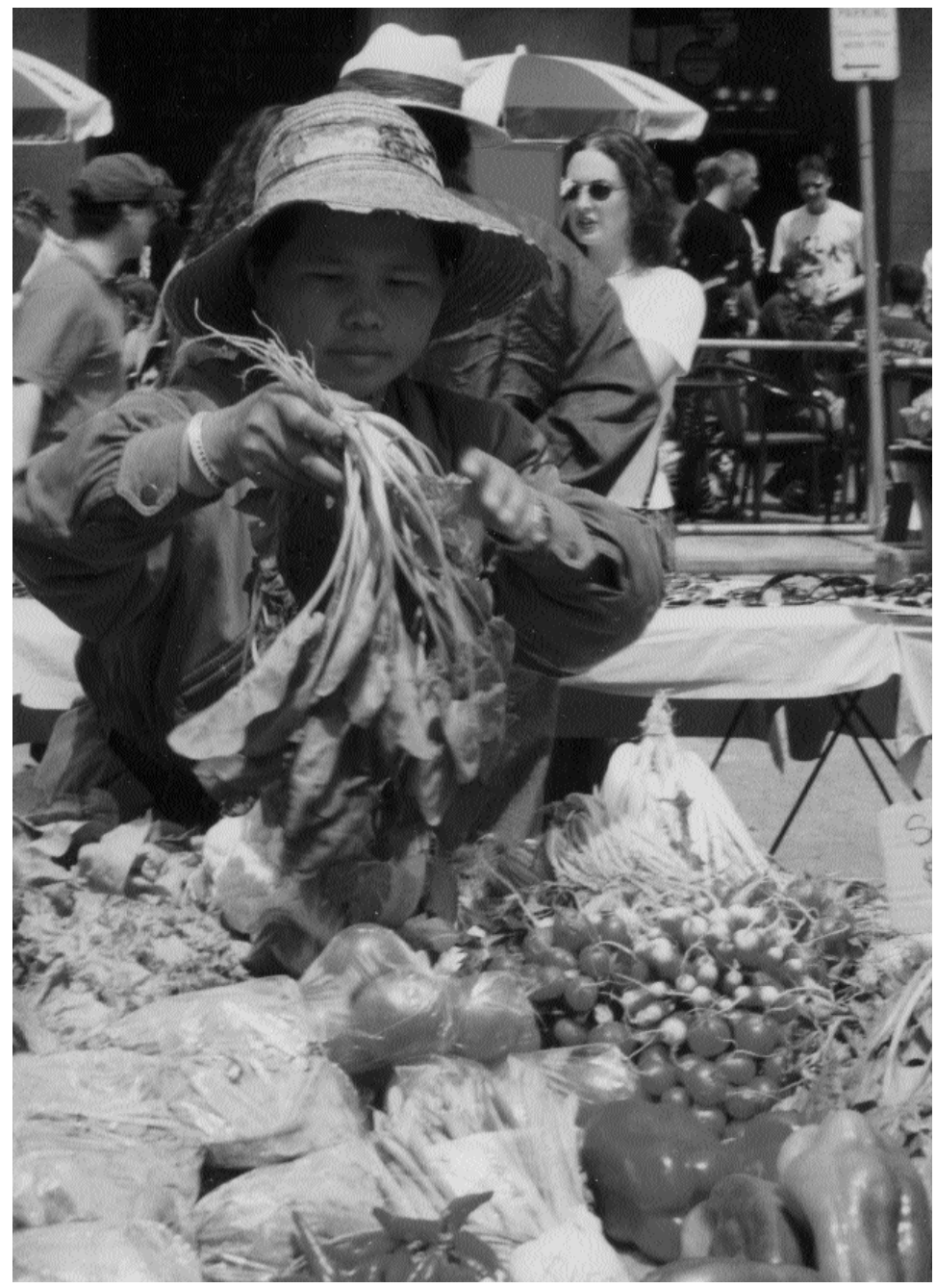

Hmong women selling vegetables at Salamanca market, Hobart, 1997. Photography by Roberta Julian. 
has been the establishment of small market gardens. The vegetables are sold on Saturdays at the market by groups of Hmong women and children who are popular subjects of the 'tourist gaze' (Urry 2002). Many visitors to Hobart would have a photograph or two of 'the Hmong at Salamanca' in their memoirs.

For Tasmanians, the Hmong at Salamanca Market symbolise a new openness to Asia, a 'new' Tasmanian identity which is inclusive of those of Asian origin. Importantly, the happy faces at the market lead Tasmanians to assume the Hmong have integrated 'easily'. This image belies the economic hardships and settlement difficulties experienced by almost all the Hmong. Nevertheless, it is a successful identity narrative which receives support from Hmong leaders as it indicates acceptance by Tasmanians.

Insofar as the Hmong are accepted as Tasmanians, however, their identity has become commodified, trivialised and marginalised. It is a superficial Hmong identity that is understood and accepted as part of the Tasmanian cultural landscape. Thus many Hmong continue to feel that they are misunderstood in their attempts to deal with mainstream service providers. They therefore continue to seek opportunities to engage in a 'presentation of self' on their own terms. This leads into a national strategy which I will address below.

In short, at the local level 'identity work' focuses on 'maintaining cultural identity'; that is, on maintaining an 'authentic' Hmong identity in an Australian context. This identity is essentialist. It is largely controlled by male leaders and is subsequently resisted and renegotiated by Hmong youth, particularly young women. Tasmanians have accepted a superficial, trivialised version of Hmong identity to incorporate into their newly emerging 'identity with many faces', one of which is an Asian face (considered essential for the tourist market).

The Hmong community's struggle to establish liminal sites for a more 'authentic' local Hmong identity reflects the process of identity construction at various levels. Suggested sites include the development of a 'traditional' Hmong village as a tourist attraction, and the establishment of a Hmong burial site in a valley about forty minutes out of Hobart. 


\section{'Identity Work': The National Level}

In the late 1990s, 78 per cent of the Hmong in Hobart were either Australian citizens or had applied for Australian citizenship (Julian et al. 1997: 48). To what extent do they identify as Australian? What does it mean to be Australian for the Hmong in Hobart?

The short answer is that the Hmong in Hobart, at least, do not identify as Australian. Unlike in other areas of Hmong settlement in Australia, they have minimal interaction with other Australians. Most adults do not work and most children mix with other Hmong at school. For example, when discussing his friends outside the Hmong community a young man noted:

But those friends are not personal friends. We might have something in common but I still feel detached when I am with them. The things that they do still do not feel right with me.

The Hobart Hmong constitute a close-knit community which is isolated from the wider society. As one Hmong man stated:

He says [as] for Australian friends, he doesn't speak much English and [so] doesn't have many. But with the Hmong, everyone is good to everyone. (Through interpreter.)

As a result of limited English language skills they have limited access to information. In the words of a Hmong man:

In Laos I like to listen to the radio and read the newspaper to understand and know what was happening ... but when we came to Australia we watch the TV but we don't understand and don't know anything that is going on ...

When they must deal with Australian institutions many find these bewildering and some have difficulty understanding Australia's social and political system. As a consequence, many do not feel a sense of security about the future. Rather, they express fear and uncertainty with respect to future government changes evident in, for example, recent concerns over the suggestion that welfare payments may disappear in the future. In short, they fit well Schutz's (1974) description of 'the stranger'. 
The lack of autonomy and control experienced by Hmong men in Hobart expresses itself most dramatically in a pervasive anxiety about the future. This is evident first in a strong concern over whether their own security as welfare recipients can be maintained indefinitely in the context of changing governments, and secondly in their recognition that their children are changing to fit into a society and a future that they cannot envision. The following quotations are indicative of these views:

He said he came here to settle but because he doesn't speak the language it is hard. And he doesn't know what to do. He lives like this every day. He doesn't know about the future or what will happen. He feels worried. (Through interpreter.)

The children act differently here than how they grow up in Laos ... They go to school, they learn different things than they learn in Laos. In Laos they grow up and they stay home with you ... Also in Laos they can help the parents.

Two main problems. Firstly, the language. If you don't speak so well you need someone to go with you. And secondly, you rely on social security money. If they stop one day and don't pay, how are you going to survive?

Our biggest worry is the children ... whether they will be able to learn at school, and whether after school they will be able to get a job ... And also our biggest problem is because we don't know the language we don't know how we're going to be in a few years time.

On the other hand, those who arrived as young men and women and were educated in Tasmania demonstrate a greater degree of confidence with respect to planning for the future. As one man stated:

Lots of plans for the future. I want the Australian government to recognise that we were part of the contingency for the Vietnam War and I want our people 
to march on Anzac Day as part of that group. I want us to be able to practise our rituals openly and share it with everyone rather than behind closed doors ... I also want all my people to be self-sufficient and independent of social welfare.

Despite such expressed ideals, the construction of a hybrid Hmong-Australian identity is problematic. Pride in Hmong culture is commonly expressed. However, in the current situation, it is felt difficult, if not impossible, to be Hmong and Australian simultaneously because some Hmong practices are illegal. Importantly, many of these 'illegal' practices are those considered central to Hmong identity. The illegal status of these practices thus constitutes a major barrier to what is seen as 'becoming Australian'. The difficulties experienced in this endeavour are illustrated in the following comments:

Some [customs] we haven't been able to continue because of Australian laws but some we can do ... There is a problem that we sometimes need to use live animals for some of our practices. The animals are used to find lost spirits. It is not sacrifice.

We are trying to submit some documents to the government for this kind of approval. It is still very difficult for us because the [Hmong] community in Australia is still very small. The practices here are not well known. In America there are more people who have cured a number of American people and my feeling is that if we could access those people it would be very helpful.

At the core of Hmong culture lies a system of religious beliefs and practices that is intertwined with holistic medicine. In explaining this belief system, a Hmong person used the analogy of a car and its driver. He explained that if sickness occurs, it could mean:

... one of our spirits has got lost or that one of our spirits has been injured ... We try to heal the spirit first ... Let me use the analogy of a car ... The driver is like the spirit. 
If the driver got lost the car can't move anymore. So somebody must find the driver of the car so it can move again.

Thus, to a large extent, the maintenance of Hmong culture is dependent upon the maintenance of Hmong health and religious practices. The Hmong recognise that, in a multicultural society, such practices need to be integrated into the Australian way of life. They are therefore keen for Anglo-Australians to embrace their holistic health practices, if not the religious beliefs that underlie them. This is clearly evident in the following quotations from interviews with Hmong in Hobart:

Probably the most important thing to me is to be allowed to practise our religion freely without any restrictions ... That is what I want and that is what I think every Hmong member here wants.

My biggest thing in life is to be able to say: 'This is my culture, this is why we practise it and this is the reason we believe it. You are welcome to come and join it if you believe in shamanism. If you are sick our shaman is there to perform it if you want it.' That is the kind of message.

To be honest with you there are some practices that we are unable to do ... For example, if somebody dies we have to leave the body exposed for one or two days and we can't do that. So we have to change that. The grave has to be in a certain position with a certain mountain so that when the person is reincarnated into his or her future they have a much more beneficial life. We have to change that too ... The way you face a dead person is important. There has to be a mountain at the end to rest his foot on and a mountain at the back to rest his head on and a mountain on the side so he can reach for it. This is very important for a Hmong person.

At the national level, the Hmong have explored strategies aimed at exposing Anglo-Australians to the benefits of their healing practices. They have thus embarked on a project which 
involves defining their practices in such a way that they are encompassed under the rubric of 'alternative medicine'. This is perceived as one way of legitimising the practices central to the Hmong which, if accepted more widely, may create a space for the emergence of a Hmong-Australian identity.

\section{'Identity Work': The Regional Level}

Historically, the Australian identity has been constructed with Asians as the 'Other' (Ip et al. 1994, Ang 2000). The White Australia policy was not officially abandoned until the mid 1970s. With increased Asian immigration to Australia since the 1970s, the 'Other' is now clearly visible within our national boundaries, as recent political events within Australia have made clear. This raises significant challenges for the reconstruction of an Australian national identity that acknowledges Australia's geographical location in the Asia-Pacific region.

The Hmong in Australia are aware that they are viewed as Asian. In addition, they are aware that 'Asians' are often viewed negatively, whereas the Hmong are viewed positively. Day-to-day interaction with Asians is often discriminatory and racist. This is partly why, at a local level, the Hmong are at pains to establish a clearly defined Hmong identity.

However, the Hmong leaders are also politically astute. Politics is also part of being Hmong. They were politically active in Laos and they continue to be politically active in 'the West'. They are aware of their status as a very small ethnic minority with low socio-economic status. They are struggling to improve their status as a community. In doing so, they are aware that they need to grow. This has been part of the motivation for continued sponsorship of Hmong from Thai refugee camps (until the final closure of the camps in 1995).

In addition, they have invited Laotian immigrants to Hmong functions. In Melbourne, some Hmong have married some Laotians. However, many Hmong state that they wish to distinguish themselves from Vietnamese, almost certainly for political reasons dating back to the conflicts in Laos. Some Hmong 
in Hobart have stated that they would prefer not to live in Melbourne because 'there are too many Vietnamese there'. Links with Laos have been limited to date because of the unsettled nature of the political situation. Nevertheless, as the situation calms down these ties are likely to increase. One family in Tasmania has recently returned to Laos for a visit.

In short, given the small size of the Hmong communities in Australia, an Asian identity is being embraced for political purposes, although historical antipathies remain which make the construction of an inclusive Asian identity problematic. The Asian identity constructed by the Hmong is a contingent one.

\section{'Identity work': The Global Level}

Since 1975 Hmong refugees have settled in the United States, France, Australia, Canada and French Guiana. There are also Hmong in China, Thailand and Vietnam.

When I originally began exploring the question 'who are the Hmong?' I discovered a highly visible, well articulated and almost unitary narrative. The same story emerged in books and videos, as well as in interviews with Hmong in Australia and in the United States. I would argues that this is a hegemonic discourse emanating from Hmong-America which is adopted by Hmong throughout the diaspora. Hmong leaders in the United States organise national and international conferences on an annual basis and have earned the support of politicians and academics. They communicate with Hmong throughout the world and are eager to construct a unified Hmong identity at this level.

Gary Yia Lee, an Australian Hmong with a $\mathrm{PhD}$ in anthropology, articulates this goal clearly in one of his articles on the internet:

The ability to travel freely to other countries where Hmong live and the informal Hmong mass media have allowed the Hmong people to rediscover each other, to see each other on videos. 
The Hmong, no matter where they are, need to know that the total sum is always bigger than its parts: the overall global Hmong identity is greater than its many local differences and groups ... The biggest challenge for all Hmong is ... to turn our diverse language and customs into one unified and one Hmong/Miao identity ... (Lee 1996).

So, what precisely are the characteristics of this global identity narrative? Who is involved in its construction?

The dominant identity narrative could be described as the quintessential 'refugee story' - a version of the well known 'immigrant success story'. It is a 'heroic' narrative that incorporates a number of themes:

- $\quad$ the war and the military (the starting point for the diasporic narrative);

- $\quad$ the refugee experience (including flight across the Mekong River and languishing in Thai refugee camps for many years);

- continuity with the past through recognition of the value of clan ties and 'traditional' Hmong culture (for example, shamanism);

- symbols of movement into the future (the modern or the postmodern) by emphasising the many educational achievements there have been.

\section{The War and the Military}

In this dominant narrative, Hmong identity is forged on a past relationship with the United States in Laos. The Hmong are provided with a unique identity vis-à-vis America, establishing and reinforcing a relationship of patronage. In general, this has been a successful strategy for Hmong-Americans, 'voiced' loudest and most articulately by Hmong male elites. It is often articulated in books about the Hmong in America, as illustrated in the following opening paragraph, based on the translation of an interview with a Hmong man, Chia Koua Xiong: 


\section{Who are the Hmong?}

In Laos, we helped you fight the war. The Americans came to live with our leaders in our country ... We provided food ... If the Americans came to our house, whatever we ate we treated the Americans equally ... If we found an injured soldier ... we ... carried the American to the base ... In some dangerous situations we were willing to let ten Hmong soldiers die so that one of your leaders could live ...

We considered Americans as our own brothers ... Now we have lost our own country ... Those who made it here, they have the opportunity for education and jobs ... We started a new life so that our children would have a better life (Pfaff 1995: 7).

Numerous videos and books recount the same story of the Hmong exodus from Laos to resettlement in the West: first, of a 'brotherhood' with United States' citizens as a consequence of fighting side by side in the Vietnam War; and second, of 'successful' adaptation to American society (evidenced by educational success) alongside the maintenance of 'traditional' cultural practices (such as shamanism).

There are two popular heroes of this narrative, in particular, who are often taken to represent the link with the past and the move into the future, although of course there are other elite Hmong leaders in Thailand, Vietnam and China. Both of these now reside in the United States. The first is General Vang Pao, acknowledged leader of the Hmong diaspora, who symbolises the military basis of the Hmong identity. The other hero is Dr Yang Dao, the first Hmong to receive a doctorate of philosophy, who is considered the patron of Hmong education and symbolises the way ahead.

While this narrative is predominantly articulated by male elites, it is also enacted and perpetuated by ordinary men and women. For example, women have reproduced this narrative in the 'storycloth' (paj ndau), a form of needlework first made around 1976 in Ban Vinai refugee camp (Anderson 1996: 30). Commonly, 
the storycloths chronicle village life in the mountains of Laos, depict religious ceremonies, or illustrate Hmong folktales. The majority created in the 'West' or for the Western market, however, recount the transition from village life prior to the war, through the escape from Laos after the war, to life in refugee camps in Thailand and often 'end' with an image of the plane in Bangkok that was to take them to 'freedom' in the United States. As Anderson (1996: 28) states:

The storycloths are a link with the past. They are shared memories captured in visual images, with the embroiderer's needle rather than the camera or the written word. As episodes of social history, they record and pass on information about Hmong customs to the younger generation, especially those born in the United States with no first-hand knowledge of Laos ... They are a form of non-verbal communication that transcend [sic] language barriers (1996: 28).

\section{The Refugee Experience}

Public events involving Hmong almost always contain accounts of refugees enduring forced migration. Typical is the following keynote speech, from the Fourth Annual National Hmong Conference held in Denver, Colorado in April 1998. Dr Mymee Her, a young Hmong psychologist from California, declared:

The Hmong are classified as REFUGEES ... Hmong refugees come to the United States wounded. Most have been beaten up physically and emotionally. They seek out shelter from whatever country will offer them safety. They have no anticipation of what life holds for them in the country of refuge. They are in a state of shock, not realising what had just happened (Her 1998).

The main focus of such narratives is on maintaining continuity with the past while taking advantage of opportunities for educational and material success in the West. Thus, Her began her speech by intoning: 
When I was asked to deliver a keynote address ... I was told that the conference theme was living the American dream. I was ecstatic, relieved that for once I did not have to talk about the struggles and suffering of the Hmong people ... But as I sat down to think about what I was going to say ... [I realised that it is] impossible to talk about our people living the American dream without talking about the history that has brought us to America, including the struggles and sufferings everyone must endure as part of our American Dream ...

From these experiences she identifies the key characteristics of Hmong identity as those of resilience, family, adaptability, and humility. She remembers her father's description of bamboo in the wind, quoting his words:

A bamboo is a very thin tree, but it is a very strong tree. It has deep roots so that it will not be uprooted by strong wind, and its stem is flexible enough to bend in the wind.

She draws on this metaphor to describe the central characteristics of Hmong identity in the United States:

My father urged me to be like the bamboo in my approach to life. Firmly planted in my own opinions and truths, yet flexible enough to hear what others, including my mother, have to say without breaking or feeling I had everything to lose. I think this is the mind set of the Hmong people, flexible enough to adapt to change, yet firmly planted by its roots to never tip over or break ...

Family, adaptability, and humility. These are the characteristics that I think are the threads which have held us together as a nation of Hmong. And these are the threads which I think will help us endure as a people, living the American Dream.

In this narrative, the refugee experience has become central to the meaning of Hmongness in the West. The significance of this is illustrated in Her's own life history. Having married an IranianAmerican, she is often asked how she deals with their differences 
(such as religious differences). She states that she sees their shared refugee status as a unifying experience and that she has come to see this refugee experience as a defining feature of Hmong identity. On this basis she describes her husband as 'a Hmong man in the skin of an Iranian'.

\section{Continuity with the Past While Embracing the Future: Reinventing 'Tradition'}

On the one hand, the narratives recounted here support and reinforce an essentialist notion of Hmongness and encourage the maintenance of ideas of 'tradition' and 'authenticity'. On the other hand, they acknowledge the impact of 'new' experiences (such as forced migration) on the Hmong identity as a construction in progress.

This contestation over 'tradition' and its value in the context of the diaspora is evident in debates about the importance of the clan to Hmong culture. ${ }^{1}$ The is clearly apparent in the following comments from a Hmong leader in Australia:

I think clan structure and clan influence is still very strong. We keep trying to say that it should not be regarded as that strong. But it will be very hard to break that. Firstly people are so used to it. Secondly because of the clan structure the clan is interdependent. If you are my clan and I come to you with a problem you can't really refuse it. On that basis the relationship has not died. The reason we are not progressing so quickly is because we regard the clan structure as so important ... People will serve their clan first. If I was looking for someone I would look around my clan first, then go to the next closest clan. If we look at it as a practical issue it is bad. If we look at it as a social issue I don't think there is anything in the world better than the Hmong social structure ...

We say, please don't regard the clan structure as so important. That is why we are so backward ...

This clan will not die. We say it is not important but it is truly important in our hearts. 
Men's strategies in relation to marriage further reinforce 'traditional' social ties in the diaspora. A number of young Hmong men in the United States have asked me: 'How traditional are young Hmong women in Australia?' For many of these young men, their inquiries preface comments about their desire to marry more 'traditional' Hmong women than the educated, assertive, and self-assured Hmong women they meet in the United States. Rising educational levels bring these issues to the fore.

When 'traditional' Hmongness is emphasised, those in the West attempting to reconstruct it look to Thailand and Laos for 'authenticity'. For many young Hmong, visits to northern Thailand and Laos are viewed with enthusiasm and are encouraged by parents as a way of reclaiming traditional Hmongness. For some Hmong men in the West, marrying Thai Hmong women is a way of maintaining traditional Hmongness. It can be argued that the maintenance of such connections with the past involves a reinvention of tradition which takes the form of a 'strategic essentialism' (Spivak 1990, Ang 1993).

Paradoxically, this strategy serves to both inhibit and encourage change in cultural practices. For example, 'traditional' views of Hmong femininity are sustained, as Hmong women are expected to be the bearers of cultural tradition (see Julian 1998, Ganguly-Scrase and Julian 1999). So, too, gender inequalities that existed in Laos remain unchallenged. On the other hand, emphasis on links with the past has led to the (re)discovery of Hmong 'roots' in China (Schein 2000) and a consequent process of sinicisation of contemporary Hmong identity (Tapp 2000). One of the dominant signifiers of this sinicised Hmong identity is the Chinese Hmong costume, which has been increasingly adopted by young Hmong women at New Year celebrations throughout the diaspora. Significantly, the Chinese Hmong skirt is now mass-produced in China and exported to Hmong women worldwide who wear it in favour of the hand-made skirts that their mothers laboured over (Wronska-Friend, this volume). There is, in this global flow, a universalisation of a different kind of Hmong identity.

While it has greatest strategic value in the local contexts of various states in the United States, this diasporic identity is also evident among Hmong on the diaspora's periphery, particularly in 
Canada, France and Australia. The boundaries of this 'imagined community' (Anderson 1983), though, are not spatial; they are grounded in the social networks that constitute the diaspora. This is evidenced by the fact that this global narrative resonates with some Hmong in Bangkok (who communicate regularly on the internet with Hmong in the United States) and in Wat Tam Krabok (where Hmong are in receipt of financial remittances from Hmong in the United States) but not with Hmong hill-tribes in northern Thailand (Ralana Maneeprasert, personal communication, 2001).

\section{Counter-Hegemonic Discourses}

The previous section has demonstrated the existence of a unitary 'global' Hmong identity emanating from Hmong-America, one that is in evidence throughout the Hmong diaspora. However, at the global level it is also possible to identify resistances and/or challenges to the hegemonic discourse, and it cannot be said that the voices of American Hmong represent all those overseas. Such resistances arise where the narrative of the 'refugee success story' does not resonate with lived experience. The voices that arise in local contexts (both inside and outside the United States) reflect differences within the Hmong diaspora based on gender, age, class, religion, 'migrantness' and place. They are what Werbner (1998: 12) refers to as voices of 'argument and imaginative creativity'.

The voices of resistance are predominantly those of educated Hmong women. However, they have been joined more recently by the voices of Hmong youth, both male and female. The main topics of contestation and debate include clan structure, youthful marriage, cross-cultural marriage, polygamy and levirate, 'kidnap' marriages, women's education, and the significance of Hmong language for Hmong identity. New communications media, such as the internet, provide a means of reaching a global Hmong audience. There is an online Hmong journal and at least one Hmong home page in both America and Australia. Young Hmong people in the United States, Australia, Canada, Thailand and Laos discuss issues surrounding Hmong identity in various chat rooms.

The field of popular culture is a newly emerging and extremely significant site for the expression of these voices. 
Consider Tou Ger Xiong, a freelance dramatic artist and stand-up comedian. His use of rap to narrate and 'translate' Hmongness not only creates an identification with African-Americans, but posits Hmong as racial minority, rather than refugee (compare Hein 1994). Tou Ger Xiong's message of Hmongness sounds like this:

As you can see I'm Asian; yeah, I'm not black.

What I'm about to say might sound like slack,

But just lend me your ears, and hear me out,

I've come to tell you what I'm all about.

Yes my name is Tou, and I've come to say

That I'm special, talented in many ways.

Yes I know kung fu, and martial arts,

You try to go get me, man I'll tear you apart.

Yeah I'm bad, mean, and tough is my game.

They call me the master; yes, it's my name.

Well you might think it's weird, to see that I'm Asian,

Busking some rhymes on such an occasion.

Well let me tell you, how I came to be,

I was born in Laos in seventy-three.

In my culture, we sing and dance,

But I'm a style rapper, yeah I take my chance.

Yo, even though this, is my first rap,

You don't have to like it, and you don't have to clap.

To those who listen, it might be nice,

To see this Hmong boy, kickin' like Vanilla Ice

(Xiong 1998).

This perception of racial minority resonates strongly with many young Hmong in the United States. No longer defining themselves as refugees, their performances at the 2002 Hmong National Development Conference Youth Forum in Milwaukee placed a wide range of popular cultural acts on display - from break dancing to poetry. 


\section{Hmong Women and the (re)Construction of Hmong Identity}

Hmong women play a leading role in the process of 'translating' Hmongness as they resist, challenge and negotiate new constructions of Hmong femininity. For example, in 1996, a small group of young Hmong women in the United States organised themselves and then raised enough funds to enable them to attend the non-government organisations' Women's Conference in Beijing (as representatives of Hmong women throughout the world). Vang (1994: 35) discusses in some depth the ways in which Hmong in the United States have responded to young married Hmong women who have bachelor degrees and also play important roles in both Hmong and American communities. As she argues, these new female roles challenge traditional notions of femininity and masculinity thereby threatening traditional male dominance.

The processes of negotiating and constructing new identities among Hmong women occur in a wide range of social contexts. Notions of 'culture' and 'tradition' are contested not only within the private sphere but within the domains of public life: in schools, at work, in the politics of multiculturalism. More importantly, I would argue that women, rather than only being the bearers of some fixed and static 'traditional' culture, are also crucial agents in the process of reconstructing new meanings of Hmonghood. Their daily involvement in a wide range of institutional contexts leads some Hmong women to constantly challenge the gendered power relations at the core of Hmong social organisation (Donnelly 1994). Such challenges occur at all levels of social life: the interpersonal, the familial, the communal, the wider society and the global. Significantly, negotiations over the meaning of 'Hmongness' are taking place in all the countries in the West in which Hmong have settled. The transnational character of the diasporic community can thus be viewed as a resource. For example, email communication provides a transnational mechanism for constructions of 'new' Hmong femininity in the diaspora, linking solitary 'trailblazers' (Bays 1994) in Australia with their more numerous counterparts in the United States. 
New 'alternative' journals also provide a site for the construction of alternative or refashioned versions of Hmong femininity. One of these, Paj Ntaub Voice, is subtitled A Journal Giving Expression to Hmoob Voices. ${ }^{2}$ In the Winter 2001 edition entitled 'Silence' the editor, Mai Neng Moua (a writer herself), states:

When I think of silence, I hear my mother telling me not to ask so many questions, to not speak with so much passion with my hands and face or in the presence of older Hmoob men. I usually associate silence with powerlessness, punishment, and control ... silence is also peace and quiet ...

The focus of this issue is silence. The point was to give voice to those who had not been heard before, to shed light on and talk about issues that have been pushed aside or hidden. This task ... was in line with Paj Ntaub Voice's goals of encouraging Hmoob writers to write their own stories and create their own images of themselves ...

Writing and publishing for Hmoob writers are courageous acts ... Moving from saying nothing to expression, to shouting and loudness takes courage. It is, to borrow bell hook's expression, an 'act of resistance' - of refusing to remain silent, or rejecting the stories and images others have created of us, of refusing to lie down and die quietly, of 'talking back' (2001: 4).

Paj Ntaub Voice thus creates a space for the reconstruction of Hmong identity; it can serve as a tool for offering resistance and challenging the meaning of 'tradition'. This is evident in the following excerpt from Paj Ntaub Voice:

It is disturbingly ironic that although Hmong means 'free', the majority of us feel just the opposite, 'trapped'. How then, can we be Hmong? The truth is, how we lived in China, Laos, and Thailand cannot explain what we feel or justify who we are today in America. This discrepancy clearly confirms that we must redefine Hmong in the context of our contemporary issues (Cha 2001: 8). 
The following poem published in the same journal expresses another young Hmong woman's oppositional positioning in relation to her Hmong identity.

Everyday.

Between personal and professional:

The world does not consist

Of Hmong issues alone.

Even though they hit closer to home.

There is no global, 'bigger' picture

In the Hmong community.

We're all struggling.

It hurts to read the paper these days.

Between individual, family and community

Because I am a lone Hmong woman

I'm appreciated more outside of the home.

My individuality is validated.

I'm expected to compete.

Not for affection.

While my sister waits to have

A late night conversation with me,

And the dishes lie dirty in the sink.

Letters unanswered.

One more meal with the relatives, missed.

One less argument I get to hear.

Between sinner and saint:

The amorphous, ever-present double standard

That slips unacknowledged to the back of our minds.

The 'good Hmong girl' façade

I will never be able to live up to

Believe me, I've tried.

For 18 years, I've tried.

And the label I now carry

In private, in jest ...

Just another day (Yang 2001: 46). 
The importance of such sites is also evident in the opening paragraph of a contribution to Hnub Tshiab, a Hmong women's publication:

As I thought of this article, many of the issues I have faced as a single Hmong woman in her mid-twenties came to mind. Should I discuss the functional reasons why marriage is so important in the Hmong culture, especially for women? Or do I talk about the lack of eligible, older Hmong men? Better yet, should I complain about the attempts by my relatives to find me a good husband as if it were an unfortunate circumstance that I was single instead of a conscious choice? Thinking it over, though, I decided that all those questions boiled down to one fundamental truth — the Hmong community is still trying to learn how to treat the increasing number of Hmong women who, like me, are making the choice to stay single in their mid-twenties (Yang 2002: 1).

The voices of Hmong women and young people are also being heard in other arenas such as theatres and art galleries. In Minneapolis, Minnesota, the new 'Theater Mu' has become an avenue for Hmong actors and Hmong plays, and in April 2002, an alternative art gallery held an exhibition of works by HmongAmerican artists.

Importantly, an examination of the process of identity construction among Hmong women demonstrates the collective nature of these resistant and oppositional positionings (see Hall 1976/2002). Gigi Durham (1999) has criticised the common formulations of resistance among young women that often, and inappropriately, adopt a model of autonomous individuals constructing resistant readings of dominant discourses. On the contrary, she argues that this overlooks 'the crucial role of women's relationships with other women in their constructions of social reality' (1999: 215). Many of the strategies discussed above demonstrate the successful translation of Hmong identity through the collective activities of Hmong youth, especially young women.

The success of these strategies is evident in their impact on 
cultural practices. This is exemplified by 'The Sounders', a musical group whose first album, Leej Twg Lub Paj Rose, was released in 1994. In the first edition of the Hmong American Journal, journalist Pa Houa Lee explained:

They are considered by many as one of the pioneers of modern Hmong music due to the music they have created. Before Sounders, most Hmong parties were conducted in a structured and orderly manner. Eligible young women would sit in chairs at the front of the audience. When each song begins [sic], the men would go up and find an available partner to dance with ...

Then came Sounders. With their non-traditional music, they have forever changed the way Hmong parties are conducted. Their music demands new moves. Their music demands new ways of getting into and out of the dance floors quickly. For the first year or so, people were confused and wondered if they should adapt to this new music or if they should just ignore parties totally.

But then, Sounder's music became more and more enticing and before they knew it, all the front chairs disappeared and the ladies were no longer 'just available' for the convenience of men ...

As time went on and people started catching up to Sounder's innovative music, new rules were made. Now everyone is just there [at the concert] to dance and party the night away ... (2002: 36).

This brief analysis has provided evidence of dissonant, resistant, vibrant Hmong 'voices' that may run counter to the hegemonic discourse identified earlier. Unlike the hegemonic discourse that attempts to impose a unitary Hmong identity throughout the diaspora, counter-hegemonic discourses are marked by fragmentation and multiplicity.

As Hmong women respond to the economic and social processes of resettlement and challenge 'traditional' notions of Hmong womanhood they are clearly participating as active agents 
in the construction of an emergent Hmong identity in the diaspora. This global identity transcends local and national identities. It emerges out of a global, 'transcendent' lived experience while, at the same time, it is implicated in the very performance of Hmong identities at the local level.

\section{Conclusions}

\section{Hmong Identification in Australia}

In the introduction, I quoted from Denis-Constant Martin who stated: 'It takes political brokers and ordinary people ... to tangle strategies and feelings into a narrative which will raise an echo' (1995: 11) and I raised the question: who is participating in the construction of contemporary Australian identity?

I would argue that ethnic minorities need to be engaged in the process of identity construction at a national level if a new, inclusive Australian identity is to be constructed. My analysis of identity construction among the Hmong suggests that at this point, it can be argued that at least some, if not the majority, are not. The politics of Australian identity is predominantly in the hands of Anglo-Australian power brokers.

As we have seen, for the Hmong (as for many other ethnic minorities in Australia) there are a number of factors (associated with their class position) which exclude them from participating in the construction of a 'new' inclusive Australian identity. These include high rates of unemployment, limited English language ability, no access to information, and limited opportunities for interaction with Anglo-Australians, all of which contribute to the selection of adaptive strategies which serve to reinvent Hmong (ethnic) tradition in such a way that it increases the level of social closure characteristic of the ethnic community.

Limited participation in Australian society means that rather than contributing to a change in the meaning of Australian identity, the majority are not in a position to forge relationships with Anglo-Australians which create new meanings. Rather, their marginal positions and relative isolation, by leaving the process of 
identity construction to Anglo-Australians, serve to further reinforce the raced and gendered Australian identity of the past. This suggests that Asian immigration, rather than providing the opportunity for new relationships and identities to emerge, has thus far provided opportunities for the reinforcement /strengthening of Asians as 'Other'.

Identities are not only narratives but are grounded in social relationships. Changing identities are dependent upon changing relationships. Clearly, the construction of a new inclusive Australian identity can only be achieved by addressing issues of social participation alongside those of identity construction.

\section{The Hmong Diaspora}

The Hmong not only provide a case study of the difficulties associated with taking on an Australian identity as an ethnic minority in Australia; they also suggest a new way of being in advanced modernity/postmodernity. Do they provide the prototype of new identities in which the local and the global claim priority over the national? Do their difficulties in constructing a Hmong-Australian identity suggest that such multiple identities in a multicultural society are not practical? Or do they indicate that multiple identities will shift so easily that they deny labelling?

My analysis of identification processes among the Hmong in Tasmania provides the basis for some tentative but, I believe, interesting observations at the global level. Could it be that the experiences of the Hmong, rather than being indicative of a 'traditional' culture or ethnic community attempting to integrate into the Australian nation, indicate the trends in identity formation in the 'age of globalisation'? (Cohen 1996: 517). Cohen has pointed to the central features of these trends when he writes:

Certain writers have suggested that a perverse feature of globalization at the cultural level is that it has brought about both the universalization and the fragmentation and multiplication of identities. An identification with a diaspora serves to bridge the gap between the local and the global, even if the outcome is a cultural artefact rather than a political project (Cohen 1996: 516). 
Importantly, Hall argues that globalisation has two possible and alternative effects on cultural identities:

Some identities gravitate to what Robbins calls 'Tradition', attempting to restore their former purity and recover the unities and certainties which are felt as being lost. Others accept that identity is subject to the play of history, politics, representation and difference, so that they are unlikely ever again to be 'pure'; and these consequently gravitate towards what Robbins (following Homi Bhabha) calls 'Translation' (1992: 309).

Significantly, the paradox of the Hmong is that they are engaged in both processes. It is through a reassertion of 'tradition' at the global level, together with the resistance and negotiation undertaken by the next generation (especially women), that new local Hmong identities are emerging in the context of the diaspora. Perhaps this is true of all diasporas and contributes to their success as a form of organisation in the 'age of globalisation'. In the meantime, for the Hmong, participation in the construction of an emergent Australian identity, capable of including its traditional 'Other', remains problematic.

To conclude, this chapter has shown the complexity of Hmong identification processes at local, national, regional and global levels. It is worth noting at this point, that over the past five years many of the Hmong have been leaving Tasmania, with the majority resettling in Queensland. The major reasons for this relate to greater employment opportunities together with factors relating to clan politics. These secondary migrations within Australia will have significant consequences for the contours of the local/global dimensions of Hmong identity in the diaspora. In the context of the analysis presented here, such changes highlight the fact that: 
Cultural boundaries are not etched in stone but have slippery divisions dependent on the self-adopted labels of groups. What seems clear is that, far from an end to history, or the loss of the subject, identity politics and cultural preservation are going to be among the hottest issues of the next century that will be fought out internationally and intra-nationally, with profound political and economic consequences (SrebernyMahommadi 1991: 135). 


\section{Footnotes}

${ }^{1}$ For example, there are many Hmong who are Christians.

${ }^{2}$ This journal, like the American Hmong Journal, is a bilingual production aimed largely at young, educated Hmong. Noog Liaj Noov Luv, printed in French Guyana and with contributions from Hmong in France, Laos, Thailand and China, is a truly global Hmong publication (Eds). 